\title{
O EXERCÍCIO DOS DIREITOS POLÍTICOS PELA PESSOA COM DEFICIÊNCIA INTELECTUAL
}

\author{
Exercise of political rights by persons with intelectual disabilities
}

\author{
Adenildo Junior Machado
}

Orientador: Jorge Irajá Louro Sodré

Resumo: O presente artigo aborda o exercício dos direitos políticos pela pessoa com deficiência intelectual e lembra que distúrbios mentais e deficiências intelectuais são uma realidade que aflige ao menos $10 \%$ da população, fazendo, direta ou indiretamente, parte do cotidiano de todos. O autor contextualiza o tratamento conferido às pessoas com deficiência mental ao longo da história, e conceitua a deficiência intelectual e as deficiências mentais. Os direitos políticos assegurados tanto pela Convenção de Direitos da Pessoa com Deficiência quanto pelo Estatuto da Pessoa com Deficiência, sob a ótica do direito constitucional, também são postos em perspectiva. Expõe como o Tribunal Superior Eleitoral tratou da matéria, e por fim, projeta qual seria o tratamento mais adequado a ser conferido pelo judiciário.

Palavras-chave: Direitos políticos. Pessoa. Deficiência intelectual.

\begin{abstract}
This paper addresses the exercise of political rights by people with intellectual disabilities and highlights that this problem, as well as mental disorders, already affects at least $10 \%$ of the population, impacting everyone's lives direct or indirectly. The author puts into context the treatment that has been given to people with mental disorders throughout history and makes an attempt to conceptualize intellectual disability and mental disability. Political rights assured by the Convention of the Rights of Persons with Disabilities and by the Statute for the Person with Disability, under the Constitutional Law point of view, are also put into perspective. In addition, it was made a research of the way the Superior Electoral Court has been dealing with all these questions. At last, this article is a humble effort to find out which treatment would be most suitable to solve the issue by the Judiciary.
\end{abstract}

Keywords: Rights politicians. Person. Deficiency. Intellectual. 


\section{Introdução}

De acordo com o Atlas de Saúde Mental 2014, da Organização Mundial da Saúde (OMS), 10\% da população global tem distúrbios de saúde mental, o que representa em torno de 700 milhões de pessoas (GELBERT, 2015). Ainda segundo dados do Instituto Brasileiro de Geografia e Estatística (IBGE), 6,2\% da população brasileira tem algum tipo de deficiência, e, especificamente, $0,8 \%$ da população tem algum tipo de deficiência intelectual, sendo que a maioria já nasceu com tais limitações. E, "do total de pessoas com deficiência intelectual, mais da metade $(54,8 \%)$ tem grau intenso ou muito intenso de limitação e cerca de $30 \%$ frequentam algum serviço de reabilitação em saúde" (VILLELA, 2015, online). São pessoas que, em passado recente, foram segregadas, maltratadas e, quando muito, tratadas como objeto de caridade.

Afere-se, assim, o quantitativo de pessoas atingidas diretamente por essa condição, sem contar os familiares, e, por fim, a comunidade em geral, que tanto pode se beneficiar dos comportamentos inclusivos quanto sofrer as consequências de uma realidade discriminatória e segregadora.

Nesse contexto, o Brasil recepcionou a Convenção sobre os Direitos das Pessoas com Deficiência e seu Protocolo Facultativo (Convenção de Nova Iorque), assinados em Nova Iorque, em 30 de março de 2007, pelo Decreto Legislativo $n^{\circ}$ 186, de 9 de julho de 2008 (BRASIL, 2008). Este com status de emenda constitucional, em razão da aprovação, em cada Casa do Congresso Nacional, em dois turnos, por três quintos dos votos dos respectivos membros (art. $5^{\circ}, \S 3^{\circ}$, da Constituição).

Com a assinatura de 161 países à Convenção e 92 países ao Protocolo Facultativo, segundo informações atualizadas até o fechamento deste artigo (ONU, 2018), poder-se-ia pensar que, finalmente, essas pessoas foram alçadas a um novo patamar de respeito e dignidade. As barreiras do preconceito e das práticas históricas de discriminação, contudo, impedem, inclusive no Brasil, no qual a recepção se deu sob o status legislativo mais nobre de emenda constitucional, de uma real transformação social.

Especificamente na Justiça Eleitoral, onde se deve garantir o exercício político, a pessoa com deficiência intelectual sofre entraves burocráticos que não condizem com as garantias da Convenção de Nova Iorque e de nosso Estatuto da Pessoa com Deficiência (Lei n ${ }^{\circ}$ 13.146/2015). 
Assim, o presente trabalho propõe uma reflexão sobre a decisão do Tribunal Superior Eleitoral no Processo Administrativo 114-71, o qual orienta a Justiça Eleitoral quanto ao tratamento a ser dado às pessoas com deficiência no condizente às anotações de suspensão de direitos políticos nos históricos cadastrais, à luz do princípio constitucional da dignidade da pessoa humana.

$\mathrm{O}$ tema ainda se justifica pela necessidade de se difundirem esses direitos da pessoa com deficiência, de forma que haja efetividade na aplicação dessas garantias constitucionais. $\mathrm{O}$ estudo do tema visa contribuir para a conscientização e difusão do ideário inclusivo, a partir da análise e da conceituação da deficiência intelectual, servindo-se de histórias e relatos de pessoas com deficiência intelectual que conseguiram superar as barreiras e estabelecer convívio social producente, para nos aproximarmos da realidade fática dos indivíduos e das famílias envolvidas. Sob esse viés, aborda os direitos e as garantias da pessoa com deficiência intelectual para gozo de seus direitos políticos.

\section{Deficiência intelectual}

\subsection{Referencial histórico}

A deficiência intelectual acompanha toda a história da humanidade. A princípio, era atribuída à intervenção dos deuses da Antiguidade, os quais eram tidos como responsáveis pelas atitudes desarrazoadas de seus súditos. Mais tarde, sob a influência do cristianismo, foi associada ao domínio pelas forças demoníacas, significando o distanciamento do homem de Deus, seu criador (PESSOTTI, 1995).

Conforme Pessotti (1995), a deficiência foi identificada como atitudes que destoam do comportamento predominante em determinada épo- ca e local, a não se vislumbrar outra alternativa que não a segregação. Nas palavras do médico Pinel, já no século XIX:

(...) Todo pudor desaparece, o vício se mostra sem recato (...) os infelizes ridicularizam todos os processos repressivos aplicados. Assim não resta outra coisa senão confiná-los em pavilhões isolados e abandoná-los às indecências sugeridas pela sua depravação, de modo a que não possam contagiar outros com o seu exemplo. (TRAITÉ, 1809 apud PESSOTTI, 1995, p. 150) 
A própria conceituação de doença mental está associada ao comportamento e à visão dominantes de determinada época e local (RAPOPORT; ARLAQUE; PETRARCA, 1993, p. 94):

(...) muitas das pessoas que atualmente são classificadas como doentes mentais são, na realidade, divergentes da sociedade. Estas pessoas que diferem de seus semelhantes, que perturbam ou escandalizam a sua família ou a sociedade são, muitas vezes, perseguidas e rotuladas como insanas, sendo levadas a internamento e tratamento involuntário.

No entanto, muitas vezes, nem precisam essas pessoas representar um papel de divergência para serem declaradas loucas, pois esta desadaptação psiquiátrica, na opinião de Szasz (1978), atende às necessidades dos membros mentalmente sadios do grupo.

É recente na história, portanto, a concepção do louco como doente mental e a associação da exclusão como forma de controle social do diferente:

Criam-se (e isto em tôda a Europa) estabelecimentos para internação que não são simplesmente destinados a receber os loucos, mas tôda uma série de indivíduos bastante diferentes uns dos outros, pelo menos segundo nossos critérios de percepção: encerram-se os inválidos pobres, os velhos na miséria, os mendigos, os desempregados opiniáticos, os portadores de doenças venéreas, libertinos de tôda espécie, pessoas a quem a família ou o poder real querem evitar um castigo público, pais de família dissipadores, eclesiásticos em infração, em resumo todos aquêles que, em relação à ordem da razão, da moral e da sociedade, dão mostras de "alteração" (FOUCAULT, 1975, p. 78).

Muito provavelmente, se um cidadão daquela época desembarcasse no tempo de hoje, sentir-se-ia compelido a internar praticamente toda a população considerada "normal" pela sociedade contemporânea.

É sob a doutrina do Dr. Pinel que se criaram os sanatórios, entre os quais o Hospital Colônia de Barbacena - MG, relatado no documentário Holocausto Brasileiro (HOLOCAUSTO, 2016), o qual chegou a abrigar, em um mesmo período, 5 mil pacientes e que, ao longo de oito décadas, vitimou mais de 60 mil pessoas. Fotos de Napoleão Xavier, de 1979, no citado filme, ilustram o depósito de pessoas que caracterizava o local, onde técni- 
cas de eletrochoque eram aplicadas nos pacientes, em sua maioria negros, para lá enviados sem que sequer houvesse certeza da existência de doença mental ou deficiência intelectual. Apenas para ilustrar as atrocidades no período, mais de 1800 cadáveres do hospital foram vendidos à Faculdade de Medicina de Valença entre 1969 e 1980; e, ao lado do hospital, eram despejados os mortos, sem identificação, em valas comuns, na sua maioria desfalecidos por inanição, frio e maus-tratos.

A partir de denúncias, como a realizada por Helvécio Ratton no documentário brasileiro Em nome da razão, de 1979, foi possível o enfrentamento e a superação desse período sombrio. No documentário de 23 minutos, é demonstrado o abandono e o "ócio absoluto" a que eram sujeitos os pacientes degradados física e moralmente. O propósito não era a cura, mas a espera da morte. Nas palavras do diretor, "em nome da razão, confinamos os esquizofrênicos, mendigos, homossexuais, drogaditos e outros dissidentes sociais" (EM NOME..., 1979), demonstrando todo o poder de opressão da sociedade contemporânea.

A reforma psiquiátrica, em parte em resposta às críticas jornalísticas, culminou com a edição da Lei nº 10.216, de 6 de abril de 2001, que dispõe sobre a proteção e os direitos das pessoas portadoras de transtornos mentais e redireciona o modelo assistencial em saúde mental para o que é aplicado atualmente.

\subsection{Conceituação}

A Convenção sobre os Direitos das Pessoas com Deficiência foi importante avanço nos direitos humanos, pois, a partir dela, as pessoas não são definidas pela sua deficiência. Esta é apenas uma condição que as diferencia das demais, sem, contudo, significar incapacidade para os atos da vida civil. O foco não está mais na deficiência, nos impedimentos, mas, sobretudo, nos obstáculos, nas barreiras sofridas por essas pessoas, prejudicando sua interação social e pleno desenvolvimento. As pessoas com deficiência deixam de ser, assim, "objeto" de caridade, para tornarem-se "sujeitos" de direitos, capazes de decidirem o rumo de suas vidas e de atuarem ativamente na sociedade em condições iguais aos demais (ONU, 2018).

Diz-se mesmo que não há um único conceito de deficiência, pois esta depende das condições do ambiente em que a pessoa vive. Sua deficiência, portanto, está associada às adaptações ou à ausência dessas que a sociedade implementa para o pleno desenvolvimento de seus direitos. 
A deficiência, portanto, não é uma condição médica, mas o resultado da interação entre atitudes negativas e/ou um ambiente não amigável com as condições pessoais do indivíduo (ONU, 2018).

No entanto, para que tenhamos uma visão pragmática do conceito de deficiência, convém mencionar que a American Association on Intellectual and Developmental Disability - AAIDD (2017) caracteriza a deficiência mental como significativa limitação no funcionamento intelectual ou no comportamento adaptativo, a qual se inicia antes mesmo dos 18 anos de idade.

Por funcionamento intelectual, a AAID refere-se à chamada inteligência, capacidade de aprender, raciocinar, resolver problemas; por comportamento adaptativo, às habilidades sociais e práticas aprendidas no dia a dia pelas pessoas, tais como:

Habilidades conceituais - linguagem e alfabetização; conceitos de dinheiro, tempo e número; e autodireção.

Habilidades sociais - habilidades interpessoais, responsabilidade social, autoestima, credulidade, ingenuidade, resolução de problemas sociais e a capacidade de seguir regras / obedecer a leis e evitar ser vitimadas.

Habilidades práticas - atividades da vida diária (cuidados pessoais), habilidades ocupacionais, saúde, viagens / transporte, horários / rotinas, segurança, uso de dinheiro, uso do telefone (AAIDD, [2017], online).

Em 1995, a Organização das Nações Unidas (ONU) deixou de utilizar o termo "deficiência mental", passando a utilizar somente "deficiência intelectual”, para afastar possível confusão com "doença mental”, esta caracterizada pelo "conjunto de comportamentos e atitudes capazes de produzir danos na performance global do indivíduo, causando impactos na sua vida social, ocupacional, familiar e pessoal" (INSTITUTO PARADIGMA, [2017], online), não havendo necessariamente déficit cognitivo.

Deficiência intelectual e mental, portanto, são sinônimos. Adota-se, contudo, aquela denominação para que não haja confusão com as doenças mentais assim entendidas, como a depressão, o transtorno de ansiedade, o distúrbio bipolar, a demência e a esquizofrenia.

Observe-se, contudo, que a própria Convenção das Pessoas com Deficiência coloca lado a lado os termos mental e intelectual para conceituar a pessoa com deficiência: 
Artigo 1

Propósito

$[\ldots]$

Pessoas com deficiência são aquelas que têm impedimentos de longo prazo de natureza física, mental, intelectual ou sensorial, os quais, em interação com diversas barreiras, podem obstruir sua participação plena e efetiva na sociedade em igualdades de condições com as demais pessoas (CONVENÇÃO..., 2011, p. 34).

Frise-se, assim, que, apesar da necessária distinção entre doenças mentais e deficiência intelectual, a Convenção conferiu abrangência suficiente para que se garantam os direitos fundamentais também aos que sofrem com transtornos mentais severos. É o que ensina Ana Maria Machado da Costa (2011, online):

O transtorno mental severo (esquizofrenia, transtorno bipolar e outras psicoses) ajusta-se perfeitamente ao conceito de deficiência expresso no Tratado da ONU, que contempla tanto a esfera biomédica como a social. Desse ângulo a deficiência é aferida não só com o ponto de vista médico, conferindo as limitações funcionais, mas também com o foco nas barreiras impostas pelo ambiente e pelas atitudes. Ambos componentes da definição da Convenção estão contemplados, posto que são pessoas com significativos impedimentos de natureza psicossocial e fortemente discriminadas.

[...]

No Brasil, o questionamento mais comum ao reconhecimento do transtorno mental como uma deficiência é o de ser essa uma doença, não uma deficiência. Várias deficiências amplamente reconhecidas como tal, entretanto, decorrem muitas vezes de doenças, como a cegueira, por exemplo, causada frequentemente pelo glaucoma ou pela diabetes. A caxumba e a meningite podem ocasionar a surdez. A amputação de membros também deriva comumente de doenças vasculares, só para citar alguns casos. Diante dessa polêmica, merece ser relembrada a Declaração da ONU, de 1975, que proclama que as pessoas deficientes, qualquer que seja a origem de suas deficiências, têm os mesmos direitos dos outros cidadãos.

Tem-se, portanto, que tanto as pessoas com doenças mentais graves como as pessoas com deficiências intelectuais podem ser abarcadas pelo Estatuto, conferindo-se a máxima otimização possível na tutela dos direitos fundamentais que a norma contempla. 


\subsection{Estigmatização $x$ superação}

Importante referir, no que tange à conceituação, que a deficiência não deve implicar a estigmatização dos indivíduos. Não é por outra razão que não se utiliza mais a expressão "pessoa deficiente", mas "pessoa com deficiência". Determinada limitação geralmente coexiste com o fortalecimento de outras habilidades da pessoa (AAIDD, 2017). Isso significa que um sujeito com mais dificuldades com números em geral apresenta melhores condições de interação social. Ou o contrário. Não difere, portanto, da forma como as pessoas em geral se identificam com esta ou aquela área do conhecimento (humanas, exatas ou biológicas, por exemplo).

Ademais, não se pode esquecer que, independentemente do grau de deficiência, há sempre a possibilidade de, a partir das vantagens ou dos pontos positivos de apoio social ou pessoal, a pessoa apresentar superação capaz de inaugurar uma nova perspectiva da limitação existente em algum plano cognitivo (AAIDD, 2017).

No blog Deficiente Ciente, da pedagoga paulista Vera Garcia, há vários relatos de jovens e adultos que, superando as barreiras do preconceito social, conseguiram provar que suas cognições diferenciadas não são impeditivas de uma vida autônoma. Histórias como a da menina com paralisia cerebral que supera dificuldades e se consagra como pintora (GARCIA, 2017a), da jovem com paralisia cerebral que se forma em marketing e em breve começa a trabalhar (GARCIA, 2017b), do primeiro músico com Síndrome de Down a gravar um CD ocupam a página do blog (GARCIA, 2017c).

Esses casos são exemplos de superação, a respeito da qual a sociedade como um todo, mas principalmente o aplicador do direito, precisa estar ciente para que sua atuação colabore e não venha, ao contrário, representar um empecilho a mais.

No programa Como será?, da Globonews, de 19 de agosto de 2017, apresentado por Sandra Annenberg, foi abordada a Rede de Assistência Psicossocial de Aracaju, do Sistema Único de Saúde, como referência no tratamento humanizado dos pacientes. Entre muitos relatos, destacou-se o da paciente que experimentou o abandono familiar e a internação compulsória das antigas clínicas psiquiátricas, que mais se assemelhavam a presídios, em que os pacientes eram mantidos constantemente dopados e submetidos a tratamentos de choques. Encontrada na rua, desorientada 
e sem documentos, hoje, em virtude de atendimento humanizado, que alia medicação a atividades recreacionais em casas-abrigo, onde residem 7 pacientes e 3 tutores, e é estimulada a interação social com a comunidade, ela apresenta considerável melhora, o que possibilita que realize compras, ajude nas atividades domésticas e decida sobre os rumos da sua vida (COMO SERÁ? 2017).

Notícia de 24 de fevereiro de 2016 conta a história de Cristian Emanoel, jovem com paralisia cerebral e cegueira, formado em Direito, que passou na prova da Ordem dos Advogados do Brasil e deseja ser membro do Ministério Público (BOM DIA RN, 2016).

E não menos elucidativa da constante superação que podemos esperar das pessoas com deficiência é a atuação dos jovens com Síndrome de Down no filme brasileiro Colegas (2012), com Ariel Goldenberg, Rita Pork e Breno Viola, e direção de Marcelo Galvão.

O diagnóstico de deficiência intelectual não deve, portanto, significar delimitação imposta à pessoa nesta condição, mas, ao contrário, deve impulsionar a procura das adaptações necessárias ao pleno exercício dos seus direitos. Esse é o sentido da Convenção de Nova Iorque e do Estatuto da Pessoa com Deficiência, como será visto a seguir.

Ao aplicador do direito restará sempre o importante papel de aferir, no caso concreto, o grau de autonomia e independência alcançado pelo indivíduo. Logo, a prestação jurisdicional, quando disser respeito à autonomia da pessoa com deficiência, não deverá jamais estar estagnada pela coisa julgada, mas aberta às sempre desejadas superações humanas. Como leciona Trindade (1999, p. 276), amadurece o reconhecimento do "direito ao desenvolvimento" como um direito humano, não se atendo somente ao desenvolvimento da pessoa humana, "sujeito central do desenvolvimento", mas também da sociedade como um todo.

\section{Direitos da pessoa com deficiência intelectual}

\subsection{Visão sob a perspectiva dos direitos humanos}

Immanuel Kant (2005, p. 104-105), filósofo precursor dos ideais dos direitos fundamentais da pessoa humana, já ensinara:

Não há ninguém, nem mesmo o pior facínora, contanto que de resto esteja habituado a usar da razão, que não deseje, quando se lhe apresentam exemplos de lealdade nas intenções, de perseverança na 
obediência a boas máximas, de compaixão e universal benevolência (e ainda por cima ligados a grandes sacrifícios de interesses e comodidades), que não deseje, digo, ter também esses bons sentimentos. [...] O dever moral é, pois, um próprio querer necessário seu como membro de um mundo inteligível, e só é pensado por ele como dever na medida em que ele se considera ao mesmo tempo como membro do mundo sensível.

Os direitos humanos fundamentais, destarte, identificados desde o antigo Egito e da Mesopotâmia, primeiramente como "mecanismo de proteção individual em relação ao Estado" (MORAES, 2005, p. 6), evoluíram para conferir direitos prestacionais sociais aos membros da comunidade. A proteção internacional dos direitos humanos, por sua vez, desenvolveu-se de fato no pós-Guerra. "A carta da ONU de 1945 contribuiu enormemente para o processo de asserção dos direitos humanos” (MAZZUOLI, 2015, p. 72).

As Constituições dos Estados Democráticos, no século XX, passaram a prever os princípios fundamentais, e logo percebeu-se o "papel central que a pessoa humana, a partir da normativa constitucional, havia adquirido" (MORAES, 2003, p. 106-107). Pois, nas palavras de Hannah Arendt (1999, p. 332), "o que importa hoje não é a imortalidade da vida, mas o fato de que a vida é o bem supremo".

A dignidade da pessoa humana indica o que falta para realização como ser humano. Enquanto os direitos humanos são os principais meios a essa consecução. Portanto, os direitos humanos das pessoas com deficiência indicam que essas pessoas devem exercer seus direitos políticos sem que o Estado, por seus agentes e órgãos, coloque empecilhos desarrazoados em afronta à Convenção da Pessoa com Deficiência.

Não obstante, como demonstrado por Flávia Piovesan (2003, p. 322), a mera existência de instrumentos legais protetivos às pessoas com deficiência não é suficiente para efetivação dessas garantias. A solução passa pela conscientização da sociedade como um todo sobre as possibilidades existentes, deixando-se para trás os preconceitos.

A existência de instrumentos legais para tutela dos direitos políticos das pessoas com deficiência é um importante avanço para a inclusão. Contudo, esses instrumentos isolados, desacompanhados de discussão e conscientização dos agentes públicos e da sociedade, podem se tornar inoperantes, erigidos apenas a um dever ser distante e desvinculado da realidade da sociedade contemporânea que se deseja. 


\subsection{Convenção sobre os direitos da pessoa com deficiência}

A Convenção sobre os Direitos das Pessoas com Deficiência, de 30 de março de 2007 (em vigor internacional desde 3 de maio de 2008), foi recepcionada, no direito interno, pelo Decreto Legislativo $n^{\circ} 186$, de 9 de julho de 2008 (BRASIL, 2008). Foi a primeira convenção sobre direitos humanos recepcionada pelo Brasil com força de emenda constitucional e promulgada pelo Decreto n-6.949, de 25 de agosto de 2009 (BRASIL, 2009).

Logo no artigo 1, a Convenção delimita seu propósito:

Artigo 1

Propósito

O propósito da presente Convenção é promover, proteger e assegurar o exercício pleno e equitativo de todos os direitos humanos e liberdades fundamentais por todas as pessoas com deficiência e promover o respeito pela sua dignidade inerente.

Importa observar que tal convenção internacional foi recepcionada pelo ordenamento jurídico brasileiro com quórum qualificado, em conformidade com o parágrafo $3^{\circ}$ do artigo $5^{\circ}$ da Constituição, motivo pelo qual equivale às emendas constitucionais (BRASIL, 1988). A promoção da igualdade de tratamento da pessoa com deficiência é inserida no nosso ordenamento jurídico como real princípio constitucional, passando a gozar, assim, de status de mandado de otimização, o qual ordena sua realização na maior medida possível (ALEXY, 1997, p. 86).

Mesmo que assim não fosse recepcionada, contudo, há que se ter em conta que, por se tratar de convenção sobre direitos humanos, já apresentaria caráter supralegal, de acordo com entendimento consolidado do Supremo Tribunal Federal no Recurso Extraordinário nº 466.343, de 3 de dezembro de 2008.

Ao descrever a situação das pessoas com retardo mental, o professor da Faculdade de Medicina da Universidade de Nebraska, Ed Skarnulis, expõe bem a condição das pessoas com deficiência intelectual, as quais foram, historicamente, tratadas como criaturas a serem temidas e, mais tarde, simplesmente como eternas crianças, dignas de pena. Em razão disso, sofrem com esse estereótipo, o qual viola sua própria dignidade como seres humanos (DREW, et al., 1977). Necessário, portanto, essa nova perspectiva, a garantir direitos constitucionais sucessivamente negados a essas pessoas. 
É justamente pela interação do sujeito com a sociedade, com o mundo à sua volta, que se tornam possíveis a evolução e o aprendizado. Explica a professora Maria Mantoan (1997, p. 20):

$\mathrm{O}$ ato de conhecer, assim como as ações humanas mais primárias (respirar, comer, pegar e outros) precisam de conteúdos externos para que se efetivem. Todos implicam a necessidade e a possibilidade de trocas entre o sujeito e o meio físico, social, natural, cultural. Portanto, de tais trocas dependem a estruturação e o funcionamento dos diversos sistemas orgânicos que nos compõem fisicamente, entre os quais a inteligência.

A inclusão das pessoas com deficiência intelectual em todos os espectros da vida social justifica-se, portanto, não só pelas razões humanas, mas também como único caminho a ser trilhado para efetivo desenvolvimento possível desses indivíduos. Não por outra razão, a Convenção previu o reconhecimento da plena capacidade das pessoas com deficiência, bem como o caráter extraordinário e temporário pelo qual devem ser admitidas eventuais salvaguardas, nos seguintes termos (CONVENÇÃO..., 2011, p. 37-38):

Artigo 12

\section{Reconhecimento igual perante a lei}

1. Os Estados Partes reafirmam que as pessoas com deficiência têm o direito de ser reconhecidas em qualquer lugar como pessoas perante a lei.

2. Os Estados Partes reconhecerão que as pessoas com deficiência gozam de capacidade legal em igualdade de condições com as demais pessoas em todos os aspectos da vida.

3. Os Estados Partes tomarão medidas apropriadas para prover o acesso de pessoas com deficiência ao apoio que necessitarem no exercício de sua capacidade legal.

4. Os Estados Partes assegurarão que todas as medidas relativas ao exercício da capacidade legal incluam salvaguardas apropriadas e efetivas para prevenir abusos, em conformidade com o direito internacional dos direitos humanos. Essas salvaguardas assegurarão que as medidas relativas ao exercício da capacidade legal respei- tem os direitos, a vontade e as preferências da pessoa, sejam isentas de conflito de interesses e de influência indevida, sejam proporcionais e apropriadas às circunstâncias da pessoa, se apliquem pelo período mais curto possível e sejam submetidas 
à revisão regular por uma autoridade ou órgão judiciário competente, independente e imparcial. As salvaguardas serão proporcionais ao grau em que tais medidas afetarem os direitos e interesses da pessoa.

5. Os Estados Partes, no caso em que a família imediata de uma criança com deficiência não tenha condições de cuidar da criança, farão todo esforço para que cuidados alternativos sejam oferecidos por outros parentes e, se isso não for possível, dentro de ambiente familiar, na comunidade. (destaques em bold do autor)

\subsection{Estatuto da Pessoa com Deficiência (Lei no ${ }^{0} 13.146 / 2015$ )}

Em 6 de julho de 2015, sete anos após a recepção no direito interno da Convenção das Pessoas com Deficiência com status de emenda constitucional, editado o Estatuto da Pessoa com Deficiência - Lei nº 13.146 (BRASIL, 2015a).

Esse diploma teve como base a Convenção sobre os Direitos das Pessoas com Deficiência e seu Protocolo Facultativo, razão pela qual, nos pontos em que a reproduz, goza de igual força das normas constitucionais. A lei, em seus arts. $1^{\circ}$ e $2^{\circ}$, afirma (BRASIL, 2015a, online):

Art. $1^{\circ}$ É instituída a Lei Brasileira de Inclusão da Pessoa com Deficiência (Estatuto da Pessoa com Deficiência), destinada a assegurar e a promover, em condições de igualdade, o exercício dos direitos e das liberdades - fundamentais por pessoa com deficiência, visando à sua inclusão social e cidadania.

Art. $2^{\circ}$ Considera-se pessoa com deficiência aquela que tem impedimento de longo prazo de natureza física, mental, intelectual ou sensorial, o qual, em interação com uma ou mais barreiras, pode obstruir sua participação plena e efetiva na sociedade em igualdade de condições com as demais pessoas.

Uma das consequências da recepção pelo direito interno da Convenção de Nova Iorque foi a revogação de todos os incisos do art. $3^{\circ}$ do Código Civil, que tinha a seguinte redação:

São absolutamente incapazes de exercer pessoalmente os atos da vida civil:

I - os menores de dezesseis anos;

II - os que, por enfermidade ou deficiência mental, não tiverem o 
necessário discernimento para a prática desses atos; III - os que, mesmo por causa transitória, não puderem exprimir sua vontade.

A redação passou a prever uma única hipótese de incapacidade absoluta, para os menores de 16 anos: "Art. $3^{\circ}$ São absolutamente incapazes de exercer pessoalmente os atos da vida civil os menores de 16 (dezesseis) anos".

Incapacidade não pode ser confundida com deficiência. Sassaki (2005, p. 9-10) aponta as diferenças:

O conceito de deficiência não pode ser confundido com o de incapacidade, palavra que é uma tradução, também histórica, do termo "handicap". O conceito de incapacidade denota um estado negativo de funcionamento da pessoa, resultante do ambiente humano e físi- co inadequado ou inacessível, e não um tipo de condição. Exemplos:a incapacidade de uma pessoa cega para ler textos que não estejam em braile, a incapacidade de uma pessoa com baixa visão para ler textos impressos em letras miúdas, a incapacidade de uma pessoa em cadeira de rodas para subir degraus, a incapacidade de uma pessoa com deficiência intelectual para entender explicações conceituais, a incapacidade de uma pessoa surda para captar ruídos e falas. Configura-se, assim, a situação de desvantagem imposta às pessoas COM deficiência através daqueles fatores ambientais que não constituem barreiras para as pessoas SEM deficiência.

Atualmente, em atendimento ao Estatuto da Pessoa com Deficiência, a única hipótese de absolutamente incapaz, na legislação civil brasileira, passou a ser o menor de 16 anos. Por consequência, também não há mais a figura do interdito. As pessoas com deficiência, a partir de então, inserem-se entre as plenamente capazes, em um nítido esforço à inclusão social e à promoção da sua dignidade (TARTUCE, 2015).

Madruga (2016, online) explica a repercussão na vida das pessoas com deficiência:

[...] a partir do Estatuto da Pessoa com Deficiência, foram revogados os incisos II e III, do artigo 3ํ, e dada nova redação do inciso III, do artigo 4ํㅡㄹ ambos do Código Civil. Por meio da lei, tornaram-se absolutamente capazes para exercer atos da vida civil os que antes 
possuíam deficiência mental ou não detinham o necessário discernimento para a prática desses atos, passando a apenas considerar relativamente incapazes, em matéria de deficiência, aqueles que, por causa transitória ou permanente, não puderem exprimir sua vontade.

Esclarece ainda Madruga (2016) que

A autonomia individual, prevista como princípio geral na Convenção sobre os Direitos das Pessoas com Deficiência da ONU, está associada com o princípio de uma vida independente, isto é, com a capacidade de homens e mulheres com deficiência controlarem pessoalmente seus múltiplos aspectos de vida, tomando decisões e assumindo responsabilidades que the propiciem acesso aos bens materiais e imateriais inerentes a todos. Vida independente, contudo, não se traduz em autonomia absoluta, senão autonomia moral. Não significa querer fazer tudo individualmente, não necessitar de ninguém ou querer viver em isolamento, mas pleitear as mesmas opções e o mesmo controle de vida diária que os homens e mulheres sem deficiência.

O Estatuto (BRASIL, 2015a, online) reproduz a Convenção, ao reconhecer a capacidade da pessoa com deficiência, explicitando que a salvaguarda, no direito brasileiro, ocorrerá pelo instituto da curatela:

Art. 84. A pessoa com deficiência tem assegurado o direito ao exercício de sua capacidade legal em igualdade de condições com as demais pessoas.

$\S 1^{\circ}$ Quando necessário, a pessoa com deficiência será subme- tida à curatela, conforme a lei.

$\S 2^{\circ}$ É facultado à pessoa com deficiência a adoção de processo de tomada de decisão apoiada.

$\S 3^{\circ}$ A definição de curatela de pessoa com deficiência constitui medida protetiva extraordinária, proporcional às necessidades e às circunstâncias de cada caso, e durará o menor tempo possível. $\S 4^{\circ}$ Os curadores são obrigados a prestar, anualmente, contas de sua administração ao juiz, apresentando o balanço do respectivo ano.

Esta curatela dirá respeito apenas aos direitos de natureza patrimonial e negocial, não alcançando, por exemplo, o direito ao voto: 
Art. 85. A curatela afetará tão somente os atos relacionados aos direitos de natureza patrimonial e negocial.

$\S 1^{\circ}$ A definição da curatela não alcança o direito ao próprio corpo, à sexualidade, ao matrimônio, à privacidade, à educação, à saúde, ao trabalho e ao voto.

$\S 2^{\circ}$ A curatela constitui medida extraordinária, devendo constar da sentença as razões e motivações de sua definição, preservados os interesses do curatelado.

$\S 3^{\circ}$ No caso de pessoa em situação de institucionalização, ao nomear curador, o juiz deve dar preferência a pessoa que tenha vínculo de natureza familiar, afetiva ou comunitária com o curatelado.

Art. 86. Para emissão de documentos oficiais, não será exigida a situação de curatela da pessoa com deficiência.

Art. 87. Em casos de relevância e urgência e a fim de proteger os interesses da pessoa com deficiência em situação de curate- la, será lícito ao juiz, ouvido o Ministério Público, de ofício oua requerimento do interessado, nomear, desde logo, curador provisório, o qual estará sujeito, no que couber, às disposições do Código de Processo Civil (BRASIL, 2015, online).

A respeito da sobreposição de normas que regulam direitos humanos, esclarece Mazzuoli (2015, p. 308) que sempre deve ser levada em consideração a norma

[...] mais benéfica aos seres humanos em questão, pois os tratados de direitos humanos têm uma lógica de aplicação totalmente distinta da dos tratados tradicionais ou comuns, baseada na escolha da norma que mais proteja os interesses das pessoas (ao que se nomina de "princípio pro homine"). Assim, ape- sar de ter "equivalência" de emenda constitucional no Brasil, a Convenção sobre os Direitos das Pessoas com Deficiência irá prevalecer sobre a legislação interna brasileira apenas quando for mais favorável ao indivíduo, pois no direito internacional dos direitos humanos o que tem importância não é a hierarquia formal das normas jurídicas, senão o conteúdo material (e, sempre, mais benéfico) previsto indistintamente no mosaico normativo vigente num determinado Estado. 


\section{Exercício dos direitos políticos pelas pessoas com deficiência intelectual}

De fato, estão previstos na Convenção (2011, online), entre outros, os direitos à participação na vida pública e política:

Artigo 29

Participação na vida política e pública

Os Estados Partes garantirão às pessoas com deficiência direitos políticos e oportunidade de exercê-los em condições de igualdade com as demais pessoas.

No Estatuto (2015, online), o direito resta assegurado no art. 76: “O poder público deve garantir à pessoa com deficiência todos os direitos políticos e a oportunidade de exercê-los em igualdade de condições com as demais pessoas". Se a intenção fosse "instituir um programa de ação futura, o constituinte derivado teria consignado: 'O Poder Público atuará no sentido de propiciar ao deficiente [...]". Ao decidir por "garantir" o exercício dos direitos políticos em igualdade de condições com as demais pessoas, investiu a pessoa com deficiência do poder de exigir do Estado, não podendo ser descartada a hipótese de indenização, no caso de descumprimento do preceito (BARROSO, 2003, p. 150).

\subsection{Direito político ativo}

O direito de votar está inserto em várias alíneas do artigo 29 da Convenção (2011, online), exigindo-se dos Estados-Partes o seguinte:

a) Assegurar que as pessoas com deficiência possam participar efetiva e plenamente na vida política e pública, em igualdade de oportunidades com as demais pessoas, diretamente ou por meio de representantes livremente escolhidos, incluindo o direito e a oportunidade de votarem e serem votadas, mediante, entre outros:

i) Garantia de que os procedimentos, instalações e materiais e equipamentos para votação serão apropriados, acessíveis e de fácil compreensão e uso; ii) Proteção do direito das pessoas com deficiência ao voto secreto em eleições e plebiscitos, sem intimidação, e a candidatar-se nas eleições, efetivamente ocupar cargos eletivos e desempenhar quaisquer funções públicas em todos os níveis de governo, usando novas tecnologias assistivas, quando apropriado; iii) Garantia da livre expressão de vontade das pes- 
soas com deficiência como eleitores e, para tanto, sempre que necessário e a seu pedido, permissão para que elas sejam auxiliadas na votação por uma pessoa de sua escolha;

b) Promover ativamente um ambiente em que as pessoas com deficiência possam participar efetiva e plenamente na condução das questões públicas, sem discriminação e em igualdade de oportunidades com as demais pessoas, e encorajar sua participação nas questões públicas, mediante:

i) Participação em organizações não governamentais relacionadas com a vida pública e política do país, bem como em atividades e administração de partidos políticos; ii) Formação de organizações para representar pessoas com deficiência em níveis internacional, regional, nacional e local, bem como a filiação de pessoas com deficiência a tais organizações.

O Estatuto (2015, online), por sua vez, no inciso IV do $\S 1^{\circ}$ do art. 76, previu "a garantia do livre exercício do direito ao voto e, para tanto, sempre que necessário e a seu pedido, permissão para que a pessoa com deficiência seja auxiliada na votação por pessoa de sua escolha". A expressão "pessoa da sua escolha" tem significado mais amplo do que curador. Poderá ser tanto o curador, nomeado, pois, por causa transitória ou permanente, não pode exprimir sua vontade (art. 4ํ, III, do Código Civil), quanto outra pessoa da sua escolha apresentada na oportunidade.

Comemora-se essa importante previsão, pois o pleno exercício dos direitos passa necessariamente pela vida pública e política. Essas pessoas passam, a partir de então, a fazer parte do conceito político de povo, "aquela parte da população capaz de participar, através de eleições, do processo democrático, dentro de um sistema variável de limitações, que depende de cada país e de cada época" (BONAVIDES, 2004, p. 75).

Observe-se que, aliado à garantia do exercício do direito ao voto, é garantido o direito às adequações materiais e ao auxílio a esse exercício, em consonância com o próprio conceito de deficiência implícito na Convenção, pois a perspectiva, como visto, não é a limitação pessoal, mas sim os obstáculos que a sociedade impõe a essas pessoas e suas peculiaridades de expressão.

Não por outra razão, o Estatuto alterou inclusive o Código Eleitoral, para que previsse: 
Art. 135.

$\S 6^{\circ}$-A Os Tribunais Regionais Eleitorais deverão, a cada eleição, expedir instruções aos Juízes Eleitorais para orientá-los na escolha dos locais de votação, de maneira a garantir acessibilidade para o eleitor com deficiência ou com mobilidade reduzida, inclusive em seu entorno e nos sistemas de transporte que lhe dão acesso.

Por outro lado, para que o exercício do voto não represente um ônus para pessoa com deficiência mental que não dispõe dos instrumentos a fim de realizar a comunicação da sua vontade, são possíveis as seguintes opções, segundo Oliveira (2017, online):

É preciso que a Administração Pública proveja meios de facilitar que o mentalmente enfermo ou deficiente se desincumba da obrigação de votar. Os meios burocráticos à disposição do eleitor e/ou familiares são os seguintes:

(1) solicitar que seja alistado como analfabeto, nos casos em que a enfermidade ou deficiência torna o portador, na prática, incapacita- do de ler ou escrever (analfabetismo funcional) ou em razão de não terem sido alfabetizados; (2) justificar-se mediante a apresentação de atestado médico a cada pleito; (3) solicitar a dispensa do exercício do voto, com o registro da impossibilidade fática ou da onerosidade demasiada do exercício do voto no cadastro eleitoral com base na Res. TSE 21.920, de 2004.

A partir de requerimento do eleitor, de responsável ou de procurador habilitado, acompanhado de documento comprobatório da impossibilidade fática do exercício do direito ao voto, o juiz eleitoral pode conceder certidão de quitação eleitoral, com prazo de validade indeterminado (art. $2^{\circ}$ da Resolução TSE 21.920/2004).

Evita-se, assim, que o Estatuto, editado para garantir direitos às pessoas com deficiência, represente, com a sua entrada em vigor, um ônus excessivo justamente aos que visava tutelar.

\subsection{Direito político passivo}

É possível ainda, de acordo com a Convenção (2011, online), que a pessoa com deficiência exerça plenamente seus direitos políticos, neles incluído o direito de ser votado. 
Artigo 29

Participação na vida política e pública

Os Estados Partes [...] deverão:

a) Assegurar que as pessoas com deficiência possam participar efetiva e plenamente na vida política e pública, em igualdade de oportunidades com as demais pessoas, diretamente ou por meio de representantes livremente escolhidos, incluindo o direito e a oportunidade de votarem e serem votadas, mediante, entre outros:

[...]

ii) Proteção do direito das pessoas com deficiência ao voto secreto em eleições e plebiscitos, sem intimidação, e a candidatar-se nas eleições, efetivamente ocupar cargos eletivos e desempenhar quaisquer funções públicas em todos os níveis de governo, usando novas tecnologias assistivas, quando apropriado; $[\ldots]$

O Estatuto (2015, online, grifo nosso), por sua vez, em seu art. 76, prevê não só o direito de ser votado, mas também o incentivo a essa atuação:

§ 1ํ̊̀ pessoa com deficiência será assegurado o direito de votar e de ser votada, inclusive por meio das seguintes ações:

$[\ldots]$

II - incentivo à pessoa com deficiência a candidatar-se e a desempenhar quaisquer funções públicas em todos os níveis de governo, inclusive por meio do uso de novas tecnologias assistivas, quando apropriado;

III - garantia de que os pronunciamentos oficiais, a propaganda eleitoral obrigatória e os debates transmitidos pelas emissoras de televisão possuam, pelo menos, os recursos elencados no art. 67 desta Lei.

O exercício do direito político passivo não se limita à possibilidade de registro de candidatura, mas à participação na vida política dos partidos, na qual se inicia o processo democrático de escolha dos futuros candidatos, razão pela qual a Convenção e o Estatuto garantem essas prerrogativas:

Art. 29

b) Promover ativamente um ambiente em que as pessoas com deficiência possam participar efetiva e plenamente na condução das questões públicas, sem discriminação e em igualdade de oportunidades com as demais pessoas, e encorajar sua participação nas questões 
públicas, mediante:

i) Participação em organizações não governamentais relacionadas com a vida pública e política do país, bem como em atividades e administração de partidos políticos;

ii) Formação de organizações para representar pessoas com deficiência em níveis internacional, regional, nacional e local, bem como a filiação de pessoas com deficiência a tais organizações (BRASIL, 2011, online).

Art. $76[\ldots]$

$\S 2^{\circ} \mathrm{O}$ poder público promoverá a participação da pessoa com deficiência, inclusive quando institucionalizada, na condução das questões públicas, sem discriminação e em igualdade de oportunidades, observado o seguinte:

I - participação em organizações não governamentais relacionadas à vida pública e à política do País e em atividades e administração de partidos políticos;

II - formação de organizações para representar a pessoa com deficiência em todos os níveis;

III - participação da pessoa com deficiência em organizações que a representem. (BRASIL, 2015a, online)

Percebe-se, assim, que longe de serem uma mera retórica, os diplomas normativos buscam de fato uma inserção das pessoas com deficiência na vida política da sociedade, não se atendo a meros comandos genéricos, mas exemplificando como deve se dar essa participação. Robustece-se também o conceito de direitos políticos, prevendo-se a participação na vida pública como um todo, tanto no âmbito partidário como nas organizações não governamentais.

E, novamente, a perspectiva da deficiência a partir dos obstáculos que a sociedade impõe exsurge também dos comandos do exercício do direito de ser votado. Não por outra razão, é previsto o uso de "novas tecnologias assistivas". Assim, deve-se alcançar todos os meios para que essas pessoas tenham sua dignidade garantida pelo exercício de seus direitos políticos, não só eliminando barreiras, mas buscando-se instrumentos que permitam a expressão de suas ideias e vontades.

\subsection{Processo Administrativo 114-71, do TSE}

Em 25 de fevereiro de 2016, após a entrada em vigor do Estatuto da Pessoa com Deficiência, o qual teve uma vacatio legis de 180 dias, a Cor- 
regedoria do Tribunal Regional Eleitoral da Bahia questionou o Tribunal Superior Eleitoral sobre como se daria a aplicação do diploma na Justiça Eleitoral. No dia 7 de abril de 2016, acordaram os Ministros Dias Toffoli, Gilmar Mendes, Luis Fux, Napoleão Nunes Maia Filho, Henrique Neves da Silva e Admar Gonzaga, por unanimidade, em fixar orientações às corregedorias e aos juízos, nos termos do voto da relatora Maria Thereza de Assis Moura, assim ementado:

PROCESSO ADMINISTRATIVO. QUESTIONAMENTOS. APLICABILIDADE. VIGÊNCIA. LEI N ${ }^{\circ} 13.146$, de 2015. ALTERAÇÃO. ART. 30. CÓDIGO CIVIL. INCAPACIDADE CIVIL ABSOLUTA. SUSPENSÃO. DIREITOS POLÍTICOS. ART. 15, II, DA CONSTITUIÇÃO. ANOTAÇÃO. CADASTRO ELEITORAL. ANTERIORIDADE.

1. O Estatuto da Pessoa com Deficiência - Lei n 13.146, de 2015 - modificou o art. 30 do Código Civil, com a alteração do rol daqueles considerados absolutamente incapazes, circunstância que trouxe impactos no âmbito desta Justiça especializada, particularmente no funcionamento do cadastro eleitoral, cujos gerenciamento, fiscalização e regulamentação estão confiados à Corregedoria-Geral.

2. Alcançado o período de vigência do mencionado diploma legal, a incapacidade absoluta se restringiu unicamente aos menores de 16 (dezesseis) anos, os quais não detêm legitimidade para se alistar eleitores - exceção feita àqueles que completem a idade mínima no ano em que se realizarem eleições até a data do pleito (Res.-TSE $n^{\circ}$ 21.538, de 2003, art. 14).

3. Esta Justiça especializada, na via administrativa, deve se abster de promover anotações de suspensão de direitos políticos por incapacidade civil absoluta, ainda que decretada anteriormente à entrada em vigor da norma legal em referência, nos históricos dos respectivos eleitores no cadastro, de forma a se adequar aos novos parâmetros fixados.

4. Para regularização das inscrições em que o registro de suspensão de direitos políticos por incapacidade civil absoluta tenha sido feito antes da entrada em vigor da Lei de Inclusão da Pessoa com Deficiência, o eleitor deverá cumprir as formalidades previstas nos arts. 52 e 53, II, a, da Res. TSE ${ }^{\circ}$ 21.538, de 2003.

5. Expedição das orientações necessárias às corregedorias regionais eleitorais, objetivando idêntica comunicação às Corregedorias Gerais de Justiça dos Estados e do Distrito Federal e aos juízos eleitorais de todo o País 


\section{PROCESSO ADMINISTRATIVO $\mathrm{N}^{\circ}$ 114-71.2016.6.00.0000 CLASSE 26 -SALVADOR - BAHIA (BRASIL, 2016).}

Em razão dessa decisão, os eleitores com deficiência com registro no histórico cadastral de suspensão de direitos políticos em razão de incapacidade civil absoluta, anotada antes da entrada em vigor do Estatuto da Pessoa com Deficiência, permanecem com esse registro ativo.

Como consequência, esses eleitores são impedidos de: i) obter certidão de quitação eleitoral; ii) requerer as operações de revisão, transferência e segunda via; iii) exercer a garantia constitucional do voto; e iv) registrar eventual candidatura ao exercício de mandato eletivo, ou seja, exercício de direito político passivo.

Para a regularização da situação cadastral da pessoa com deficiência e, consequentemente, permitir que ela goze plenamente de seus direitos políticos ativos e passivos, a Resolução do Tribunal Superior Eleitoral - TSE $n^{\circ} 21.538$, de 2003, exige comprovação de que foi cessado o impedimento, nos seguintes termos:

Art. 52. A regularização de situação eleitoral de pessoa com restrição de direitos políticos somente será possível mediante comprovação de haver cessado o impedimento.

$\S 1^{\circ}$ Para regularização de inscrição envolvida em coincidência com outra de pessoa que perdeu ou está com seus direitos políticos suspensos, será necessária a comprovação de tratar-se de eleitor diverso. $\S 2^{\circ} \mathrm{Na}$ hipótese do artigo, o interessado deverá preencher requerimento e instruir o pedido com declaração de situação de direitos políticos e documentação comprobatória de sua alegação.

$\S 3^{\circ}$ Comprovada a cessação do impedimento, será comandado o código FASE próprio e/ou inativado(s), quando for o caso, o(s) registro(s) correspondente(s) na base de perda e suspensão de direitos políticos.

Art. 53. São considerados documentos comprobatórios de reaquisição ou restabelecimento de direitos políticos:

II - Nos casos de suspensão:

a) para interditos ou condenados: sentença judicial, certidão do juízo competente ou outro documento; [...] (BRASIL, 2003, online).

Igual exigência há para atualização do cadastro eleitoral, mediante coleta de dados biométricos, em conformidade com a Resolução do TSE $\mathrm{n}^{\circ} 23.440$, de 2015: 
Art. $7^{\circ}[\ldots]$

$\S 4^{\circ}$ Comprovada, perante a Justiça Eleitoral, a cessação de causa de restrição aos direitos políticos, na forma do ad. 52 da Res.-TSE $n^{\circ} 21.538$, de 14 de outubro de 2003, e regularizada a respectiva inscrição que figurar no cadastro eleitoral em situação de suspensão, o juízo eleitoral convocará o interessado para comparecimento ao cartório, visando à coleta de fotografia, impressão digital e assinatura digitalizada (BRASIL, 2015b).

Nossa Carta Magna prevê a suspensão dos direitos políticos no caso de incapacidade civil absoluta (artigo 15, inciso II), deixando para a legislação infraconstitucional explicitar essa conceituação.

Como visto, a Convenção dos Direitos da Pessoa com Deficiência, além de ser claramente norma de direitos humanos, foi recepcionada pelo nosso direito interno com status de norma constitucional, garantindo o pleno exercício dos direitos políticos pelas pessoas com deficiência.

Aportou ela, contudo, em um ordenamento que previa, como regra, a incapacidade civil dos que não tivessem o necessário discernimento para a prática de atos da vida civil por enfermidade ou deficiência (art. 3oㅜ inciso II, do Código Civil revogado). Assim, antes mesmo de este dispositivo ter sido revogado pelo Estatuto da Pessoa com Deficiência, já padecia do vício da inconstitucionalidade.

Os Ministros do TSE, no Processo Administrativo 114-71, contudo, optaram por estabelecer como marco para abstenção das anotações de suspensão de direitos políticos para pessoa com deficiência a entrada em vigor do Estatuto da Pessoa com Deficiência, ocorrida em 02 de janeiro de 2016 (180 dias da publicação).

Assim, para a regularização das inscrições em que o registro de suspensão de direitos políticos por incapacidade civil absoluta tenha sido realizado antes da entrada em vigor da mencionada lei, o eleitor deverá comprovar o levantamento da interdição pela Justiça Estadual ou apresentar outro documento que demonstre sua aptidão ao exercício dos direitos políticos (arts. 52 e 53, II, a, da Res.-TSE n 21.538, de 2003).

Para a pessoa com deficiência intelectual sem anotação do registro de suspensão dos direitos políticos por incapacidade civil absoluta no histórico cadastral quando da entrada em vigor do Estatuto, o TSE previu, no Processo Administrativo 114-71, que a Justiça Eleitoral deveria se abster de 
fazer qualquer registro nesse sentido, ainda que houvesse decisão judicial pretérita determinando o registro:

$[\ldots]$

3. Esta Justiça especializada, na via administrativa, deve se abster de promover anotações de suspensão de direitos políticos por incapacidade civil absoluta, ainda que decretada anteriormente à entrada em vigor da norma legal em referência, nos históricos dos respectivos eleitores no cadastro, de forma a se adequar aos novos parâmetros fixados.

$[\ldots]$

PROCESSO ADMINISTRATIVO $\mathrm{N}^{\circ}$ 114-71.2016.6.00.0000

CLASSE 26 -SALVADOR - BAHIA (BRASIL, 2016).

Destarte, com a entrada em vigor do Estatuto, mesmo as decisões judiciais que determinaram a suspensão dos direitos políticos em razão de incapacidade civil absoluta apurada em ação própria da Justiça Comum ficaram sem cumprimento pela Justiça Eleitoral.

A estas pessoas com deficiência intelectual, mas sem o registro da suspensão dos direitos políticos no histórico cadastral da Justiça Eleitoral, quando da entrada em vigor do Estatuto, ficou garantido, portanto, o amplo exercício dos direitos políticos. Fato este que representa um direito, mas também um ônus de comparecimento às urnas, que, como visto, pode ser afastado se: i) solicitar o alistamento como analfabeto; ii) apresentar atestado médico; ou iii) requisitar a dispensa do exercício do voto com o registro da impossibilidade fática ou da onerosidade demasiada do exercício do voto.

Há, portanto, uma distinção de tratamento entre pessoas em igualdade de condições. De um lado, as com deficiência com registro da suspensão de direitos políticos no histórico cadastral da Justiça Eleitoral quando da entrada em vigor do Estatuto. De outro, as também com deficiência intelectual, mas sem registro da suspensão dos direitos políticos em seus históricos cadastrais da Justiça Eleitoral quando da entrada em vigor do referido diploma.

O TSE exige que as pessoas com registro de suspensão de direitos políticos em razão de incapacidade civil absoluta comprovem a alteração da sua condição por diversas formas: a) sentença judicial; b) certidão do juízo competente; ou c) outro documento (Processo Administrativo 114-71). Às pessoas sem o registro da suspensão de direitos políticos quando da entrada em vigor do Estado nenhuma providência é exigida. 
Essa diferenciação no tratamento representa discriminação, a qual a Convenção sobre os Direitos das Pessoas com Deficiência e o Estatuto brasileiro coíbem expressamente. A própria razão de existência desses instrumentos normativos tem relação direta com a vedação a toda forma de discriminação baseada na deficiência (ONU, 2018).

Logo, todo e qualquer registro de suspensão de direitos políticos às pessoas com deficiência intelectual deve ser excluído, pois dissonante de nosso atual ordenamento. E, para que não represente ônus desmedido, deve ser anotada a impossibilidade de comparecimento às urnas. Assim, se possibilitada, de alguma forma, a expressão da vontade do eleitor, esta deveria ser respeitada.

$\mathrm{Ou}$, ao menos, que a comprovação das condições para o exercício do direito político por tais pessoas seja simplificada, bastando o comparecimento do cidadão e a solicitação do levantamento da anotação de suspensão.

Somente assim se estaria conferindo real efetividade ao Estatuto da Pessoa com Deficiência, bem como tratamento equidistante às pessoas com deficiência e sem registro de suspensão nos seus históricos cadastrais.

\section{Considerações finais}

O Estado e a sociedade têm dívida histórica com pessoas com deficiência intelectual que, durante décadas, sofreram o descaso e a violência institucionalizada, razão pela qual o Judiciário, como parte desse Estado, não pode se eximir de adotar a posição mais consentânea possível com os valores que embasaram a Convenção de Nova Iorque.

O TSE, contudo, impôs obstáculo não previsto na legislação em curso. De fato, como visto, a Convenção de Direito Internacional sobre as Pessoas com Deficiência, bem como o Estatuto da Pessoa com Deficiência, não faz objeção ao exercício dos direitos políticos pela pessoa com deficiência mental. Antes pelo contrário, explicitam serem estes direitos garantidos por instrumentos que facilitem a comunicação desses indivíduos, ficando o instituto da curatela restrita para os que, por causa transitória ou permanente, não puderem exprimir sua vontade (art. $4^{\circ}$, III, do Código Civil).

A decisão do TSE no Processo Administrativo 114-71, ao exigir que se comprove a condição de aptidão da pessoa com deficiência, contrariou e impôs ônus maior do que o presente na Convenção, que, como visto, foi recepcionada com força de emenda constitucional no ordenamento jurídico brasileiro, motivo pelo qual padece de inconstitucionalidade. 
Sobre as pessoas abrangidas por essa decisão do TSE, é verdade, pendem decisões judiciais, as quais, sob o manto do devido processo legal e do contraditório, concluíram pela interdição. O status, contudo, de incapaz e a consequente suspensão dos direitos políticos não mais subsistem no nosso ordenamento para as pessoas com deficiência intelectual.

Poder-se-ia argumentar que maior prejuízo haveria se afastada a restrição no cadastro de todas as pessoas com deficiência, impondo-se a obrigatoriedade do voto e as consequências do seu descumprimento àqueles que tiveram reconhecido judicialmente sua impossibilidade de exercí- cio dos direitos civis e, para os quais ainda não alcançados os meios paraque exerçam seus direitos políticos. É o caso, por exemplo, das pessoas em estado de deficiência intelectual grave, seja em decorrência de doença congênita, seja em decorrência de AVC ou trauma craniano, sem aparato tecnológico que lhes permitam manifestar sua vontade.

Inclusive para estas, contudo, não é mais devida a suspensão dos direitos políticos, medida extrema e associada à condição de incapaz, restrita aos menores de 16 (dezesseis) anos. Devida, portanto, é somente a anotação cadastral que as eximam das consequências de não comparecimento ao pleito. Do contrário, estar-se-á contrariando a nossa Carta Magna e a convenção de direitos humanos da qual somos signatários.

Ronald Dworkin (2002, p. 283), questionando sobre os direitos dos particulares de fazerem manifestações que perturbam a ordem pública, dissertou:

Na prática, o governo terá a última palavra sobre quais são os direitos individuais, porque sua polícia fará o que suas autoridades e seus tribunais ordenarem. Mas isto não significa que o ponto de vista governamental seja necessariamente correto. Quem quer que pense assim está obrigado a acreditar que homens e mulheres só possuem os direitos morais sancionados pelo governo, o que significa que não possuem direitos morais de espécie alguma.

Propõe-se, aqui, a exemplo da provocação de Dworkin, que pessoas com deficiência intelectual tenham seus direitos políticos restabelecidos, com anotação cadastral da dificuldade para o exercício do voto, para que eventual não comparecimento às urnas não comprometa a certificação da quitação das obrigações eleitorais. Ou que, ao menos, tenham facilitada a exclusão da anotação de suspensão de direitos políticos com simples petição. 
O esforço deve ser para que se dê o máximo de efetividade aos direitos e às garantias fundamentais, sob pena de infligirmos dano não somente a esses indivíduos, mas a todo corpo social, como ocorre sempre que atingidos os direitos humanos.

\section{Referências}

ALEXY, Robert. Teoria de los derechos fundamentales. Madrid: Centro de Estudios Constitucionales, 1997.

ARENDT, Hannah. A condição humana. Tradução: Roberto Raposo. Rio de Janeiro: Forense Universitária, 2007.

ASSOCIATION ON INTELLECTUAL AND DEVELOPMENTAL DISABILITY - AAIDD. Definition of Intellectual Disability. Washington, DC, [2017]. Disponível em: <http://aaidd.org/intellectualdisability/ definition\#.WqZaqlC5vcd>. Acesso em: 31 ago. 2017.

BARROSO, Luís Roberto. O direito constitucional e a efetividade de suas normas: limites e possibilidades da constituição brasileira. 7. ed. Rio de Janeiro: Renovar, 2003.

BOM DIA RN. Deficiente visual com paralisia cerebral se forma em Direito em Natal. Rio de Janeiro: Inter TV, 24 fev. 2016. Programa de TV. BONAVIDES, Paulo. Ciência política. 11. ed. São Paulo: Malheiros, 2004.

BRASIL. Constituição (1988). Promulgada em 5 de outubro de 1988. Brasília, DF, 1988. Disponível em: <http://www.planalto.gov.br/ccivil_03/constituicao/constituicao.htm>. Acesso em: 12 ago. 2017.

BRASIL. Decreto legislativo n. 186, de 2008. Aprova o texto da Convenção sobre os Direitos das Pessoas com Deficiência e de seu Protocolo Facultativo, assinados em Nova Iorque, em 30 de março de 2007. Brasília, DF, 2008. Disponível em: <http://www.planalto.gov.br/ccivil_03/Congresso/DLG/ DLG-186-2008.htm>. Acesso em: 31 ago. 2017.

BRASIL. Decreto n. 6.949, de 25 de agosto de 2009. Promulga a Convenção Internacional sobre os Direitos das Pessoas com Deficiência e seu Protocolo Facultativo, assinados em Nova York, em 30 de março de 2007. Brasília, DF, 2009. Disponível em: <http://www.planalto.gov.br/ccivil_03/_ato20072010/2009/decreto/d6949.htm>. Acesso em: 15 ago. 2017. 
BRASIL. Lei n. 13.146, de 6 de julho de 2015. Institui a Lei Brasileira de Inclusão da Pessoa com Deficiência (Estatuto da Pessoa com Deficiência). Brasília, DF, 2015a. Disponível em: <http://www.planalto.gov.br/ccivil_03/_ato20152018/2015/lei/113146.htm>. Acesso em: 20 ago. 2017.

BRASIL. Tribunal Superior Eleitoral. Processo administrativo n. 11471.2016.6.00.0000. Brasília, DF, 2016.

BRASIL. Tribunal Superior Eleitoral. Resolução no $\mathbf{2 1 . 5 3 8 , ~ d e ~} 14$ de outubro de 2003. Dispõe sobre o alistamento e serviços eleitorais mediante processamento eletrônico de dados, a regularização de situação de eleitor, a administração e a manutenção do cadastro eleitoral, o sistema de alistamento eleitoral, a revisão do eleitorado e a fiscalização dos partidos políticos, entre outros. Brasília, DF, 2003. Disponível em: <http://www.tse.jus.br/legislacao/codigo-eleitoral/normas-editadas-pelotse/resolucao-nb0-21.538-de-14-de-outubro-de-2003-brasilia-2013-df>. Acesso em: 31 ago. 2017.

BRASIL. Tribunal Superior Eleitoral. Resolução no 23.440, de 13 de março de 2015. Disciplina os procedimentos para a realização da atualização ordinária do cadastro eleitoral, com a implementação de nova sistemática de identificação do eleitor, mediante incorporação de dados biométricos e por meio de revisões de eleitorado de ofício, em municípios previamente selecionados pelos tribunais regionais eleitorais, e dá outras providências. Brasília, DF, 2015b. Disponível em: < http://www.tse.jus.br/legislacaotse/res/2015/RES234402015.htm>. Acesso em: 31 ago. 2017.

COLEGAS. Direção de Marcelo Galvão. Produção de Marcelo Galvão. [S.1.]: Gatacine, 2012. (94 min.), son., color. Disponível em: <https://www.youtube. com/watch?v=PogV1GwUKQs>. Acesso em: 15 set. 2016.

COMO SERÁ? SOS SUS: A rede de saúde mental que é referência no país. Rio de Janeiro: Rede Globo, 19 ago. 2017. Programa de TV.

CONVENÇÃO sobre os Direitos das Pessoas com Deficiência (2007). Convenção sobre os Direitos das Pessoas com Deficiência: Protocolo Facultativo à Convenção sobre os Direitos das Pessoas com Deficiência: decreto legislativo no 186, de 09 de julho de 2008: decreto no -6.949 , de 25 de agosto de 2009. Ed., rev. e atual. Brasília, DF: Secretaria de Direitos Humanos, Secretaria Nacional de Promoção dos Direitos da Pessoa com Deficiência, 2011.

COSTA, Ana Maria Machado da. O Reconhecimento da Pessoa com Transtorno Mental Severo Como Pessoa Com deficiência: Uma Questão de Justiça. Inclusive: inclusão e cidadania, [S.1.], 26 jan. 2011. Disponível em: <https://www.inclusive.org. br/wp-content/uploads/O_reconhecimento.pdf>. Acesso em: 5 set. 2017. 
DREW, Clifford J. et al (Orgs.). Mental retardation: social and educational perspectives. Saint Louis: The C. V. Mosby Company, 1977.

DWORKIN, Ronald. Levando os direitos a sério. São Paulo: Martins Fontes, 2002 .

EM NOME DA RAZÃO - Um filme sobre os porões da loucura. Direção de Helvécio Ratton. Produção de Tarcísio Vidigal. Realização de Grupo Novo de Cinema e Associação Mineira de Saúde Mental. Música: Evandro Lemos. 1979. (23 min.), son., P\&B. Fotografia: Dileny Campos; Montagem: José Tavares de Barros. Disponível em: <https://vimeo.com/162724580>. Acesso em: 13 set. 2017.

FOUCAULT, Michel. Doença Mental e Psicologia. Tradução de Lilian Rose Shalders. 5. ed. Rio de Janeiro: Tempo Brasileiro, 1975.

GARCIA, Vera. Jovem com paralisia cerebral se forma em marketing e em breve começará a trabalhar. Deficiente ciente, [S.1.], 1 fev. 2017a. Disponível em: <https:// www.deficienteciente.com.br/jovem-com-paralisiacerebral-se-forma-em-marketing-e-em-breve-comecara-a-trabalhar.html>. Acesso em: 17 ago. 2017.

GARCIA, Vera. Menina com paralisia cerebral supera dificuldades e se consagra como pintora. Deficiente ciente, [S.1.], 5 maio 2017b. Disponível em: <https:// www.deficienteciente.com.br/primeiro-musico-com-sindrome-dedown-gravar-cd. html>. Acesso em: 10 ago. 2017.

GARCIA, Vera. Primeiro músico com síndrome de down a gravar CD. Deficiente ciente, [S.1.], 5 maio 2017c. Disponível em: <https://www.deficienteciente.com.br/menina-com-paralisia-cerebral-superadificuldades-e-se-consagra-como-pintora.html>. Acesso em: 31 ago. 2017.

GUELBERT, Laura. OMS alerta que 10\% da população global tem distúrbio de saúde mental. Portal EBC, Brasília, DF, 15 jul. 2015. Disponível em: <http:// www.ebc.com.br/noticias/saude/2015/07/oms-alerta-que-10-dapopulacao-global-tem-disturbio-de-saude-mental>. Acesso em: 31 ago. 2017.

HOLOCAUSTO brasileiro. Direção de Daniela Arbex, Armando Mendz. Produção de Daniela Arbex. Roteiro: Daniela Arbex. Barbacena: Vagalume Filmes, Brasil Distribution, Llc, 2016. (90 min.), son., color. Disponível em: <https:// www.youtube.com/watch?v=CVMGZqV2cP4>. Acesso em: 12 set. 2017.).

INSTITUTO PARADIGMA. Qual a diferença entre doença mental e deficiência intelectual? São Paulo, SP, [20--]. Disponível em: <http://www.institutoparadigma.org.br/pergunte/particiapacao-social-edireitos/264-qual-a-diferenca-entre-doenca-mental-e-deficiencia-intelectual>. Acesso em: 1 set. 2017. 
KANT, Immanuel. Fundamentação da Metafísica dos Costumes. Lisboa: 70, 2005.

MADRUGA, Sidney. A Lei Brasileira de Inclusão e a capacidade eleitoral das pessoas com deficiência mental grave. Jota, [S.1.], 27 jul. 2016. Disponível em: $<$ https://www.jota.info/opiniao-e-analise/artigos/lei-brasileira-de-inclusaoe-capacidade-eleitoral-das-pessoas-com-deficiencia-mental-grave22072016>. Acesso em: 12 ago. 2017.

MANTOAN, Maria Teresa Eglér. Ser ou estar, eis a questão: explicando o déficit intelectual. Rio de Janeiro: Wva, 1997.

MAZZUOLI, Valerio de Oliveira. Curso de direitos humanos. 2. ed. São Paulo: Método, 2015.

MORAES, Alexandre de. Direitos humanos fundamentais. 6. ed. São Paulo: Atlas, 2005.

MORAES, Celina Bodin de. O conceito de dignidade humana: substrato axiológico e conteúdo normativo. In: SARLET, Wolfgang Sarlet (Org.). Constituição, Direitos Fundamentais e Direito Privado. Porto Alegre: Livraria do Advogado, 2003.

OLIVEIRA, Vinícius de. O voto da pessoa mentalmente enferma ou deficiente: a inclusão, o ônus e a fraude. Os eleitoralistas - Democracia e direito eleitoral, [S.1.], 5 ago. 2017. Disponível em: <http://www.oseleitoralistas.com. br/2017/08/05/voto-pessoa-enferma/>. Acesso em: 29 ago. 2017.

PESSOTTI, I. A loucura e as épocas. Rio de Janeiro: 34, 1995.

PIOVESAN, Flávia. Temas de direitos humanos. 2. ed. São Paulo: Saraiva, 2003.

RAPOPORT, Andrea; ARLAQUE, Patrícia; PETRARCA, Rita. Doença Mental: metamorfose histórica. Psico. Porto Alegre, Instituto de Psicologia da PUC Rio Grande do Sul, Porto Alegre, v. 24, n. 2, p. 94, 1993.

SASSAKI, Romeu Kazumi. Atualizações semânticas na inclusão de pessoas: Deficiência mental ou intelectual? Doença ou transtorno mental? Revista Nacional de Reabilitação, São Paulo, v. 43, p. 9-10, mar. 2005.

SZASZ, S. T. A fabricação da loucura. Rio de Janeiro: Zahar, 1978.

TARTUCE, Flávio. Manual de Direito Civil: volume único. 5. ed. rev., atual. e ampl. Rio de Janeiro: Forense; São Paulo: Método, 2015. 
TRINDADE, Antônio Augusto Cançado. O legado da declaração universal e o futuro da proteção internacional dos direitos humanos. In: AMARAL JÚNIOR,Alberto do; MOISÉS, Cláudia Perrone (Orgs). O cinqüentenário da declara-ção universal dos direitos do homem. São Paulo: Edusp, 1999.

UNITED NATIONS - UD. Convention on the Rights of Persons with Disabilities. New York, NY, [2018]. Disponível em: <https://www.un.org/ development/desa/disabilities/convention-on-the-rightsof-persons-with-disabilities.html>. Acesso em: 3 jul. 2018.

UNITED NATIONS - UD. Convention on the Rights of Persons with

Disabilities. New York, NY, [2018]. Disponível em: <https://www.un.org/ development/desa/disabilities/convention-on-the-rightsof-persons-with-disabilities/frequently-asked-questions-regarding-theconvention-on-the-rights-of-persons-with-disabilities.html>. Acesso em: 3 jul. 2018.

UNITED NATIONS - UD. Convention on the Rights of Persons with

Disabilities. New York, NY, [2018]. Disponível em: <https://treaties.un.org/ Pages/ViewDetails.aspx?src=TREATY\&mtdsg_no=IV15-a\&chapter=4\&clang=_en>. Acesso em: 5 jul. 2018.

UNITED NATIONS - UD. Convention on the Rights of Persons with

Disabilities. New York, NY, [2018]. Disponível em: <https://treaties.un.org/ Pages/ViewDetails.aspx?src=TREATY\&mtdsg_no=IV15\&chapter=4\&clang=_en>. Acesso em: 5 jul. 2018.

VILLELA, Flávia. IBGE: 6,2\% da população têm algum tipo de deficiência. Portal EBC, Brasília, DF, 21 ago. 2015. Disponível em: < http://www.ebc.com. br/noticias/2015/08/ibge-62-da-populacao-tem-algumtipo-de-deficiencia>. Acesso em: 31 ago. 2017.

Adenildo Junior Machado - Especialista em direito público pela Escola Superior da Magistratura Federal. Possui graduação em Ciências Jurídicas e Sociais pela Universidade Federal do Rio Grande do Sul (2004). Analista Judiciário - Área Judiciária do TRE-RS.

Jorge Irajá Louro Sodré - Doutor em Direito pela Pontifícia Universidade Católica doRio Grande do Sul (PUCRS). Mestre em Direito pela Universidade de Santa Cruz do Sul (UNISC). Especialista em Direitos Humanos pela Universidade Federal do Rio Grandedo Sul (UFRGS). Master em Direitos Humanos pela Universidade Pablo de Olavide/ESP. Procurador da República. 